University of Nebraska - Lincoln

DigitalCommons@University of Nebraska - Lincoln

$4-15-2011$

KINETIC STUDIES OF DRUG-PROTEIN INTERACTIONS BY USING

PEAK PROFILING AND HIGH-PERFORMANCE AFFINITY

CHROMATOGRAPHY: EXAMINATION OF MULTI-SITE INTERACTIONS OF DRUGS WITH HUMAN SERUM ALBUMIN COLUMNS

\author{
Zenghan Tong \\ University of Nebraska-Lincoln \\ John E. Schiel \\ University of Nebraska-Lincoln \\ Efthimia Papastavros \\ University of Nebraska-Lincoln, efthimia@huskers.unl.edu \\ Corey M. Ohnmacht \\ University of Nebraska - Lincoln \\ Quentin R. Smith \\ Texas Tech University Health Sciences Center \\ See next page for additional authors
}

Follow this and additional works at: https://digitalcommons.unl.edu/chemistryhage

Tong, Zenghan; Schiel, John E.; Papastavros, Efthimia; Ohnmacht, Corey M.; Smith, Quentin R.; and Hage, David S., "KINETIC STUDIES OF DRUG-PROTEIN INTERACTIONS BY USING PEAK PROFILING AND HIGHPERFORMANCE AFFINITY CHROMATOGRAPHY: EXAMINATION OF MULTI-SITE INTERACTIONS OF DRUGS WITH HUMAN SERUM ALBUMIN COLUMNS" (2011). David Hage Publications. 13.

https://digitalcommons.unl.edu/chemistryhage/13

This Article is brought to you for free and open access by the Published Research - Department of Chemistry at DigitalCommons@University of Nebraska - Lincoln. It has been accepted for inclusion in David Hage Publications by an authorized administrator of DigitalCommons@University of Nebraska - Lincoln. 


\section{Authors}

Zenghan Tong, John E. Schiel, Efthimia Papastavros, Corey M. Ohnmacht, Quentin R. Smith, and David S. Hage 


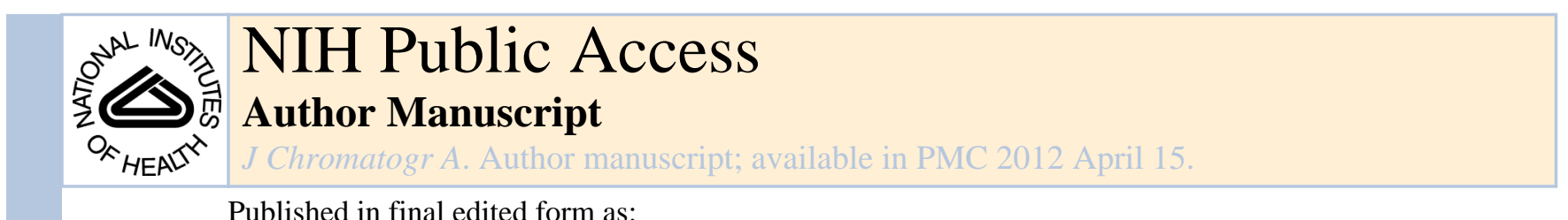

JChromatogr A. 2011 April 15; 1218(15): 2065-2071. doi:10.1016/j.chroma.2010.10.070.

\title{
KINETIC STUDIES OF DRUG-PROTEIN INTERACTIONS BY USING PEAK PROFILING AND HIGH-PERFORMANCE AFFINITY CHROMATOGRAPHY: EXAMINATION OF MULTI-SITE INTERACTIONS OF DRUGS WITH HUMAN SERUM ALBUMIN COLUMNS
}

\author{
Zenghan Tong ${ }^{\mathrm{a}}$, John E. Schiel ${ }^{\mathrm{a}}$, Efthimia Papastavros ${ }^{\mathrm{a}}$, Corey M. Ohnmacht $^{\mathrm{a}}$, Quentin R. \\ Smith ${ }^{b}$, and David S. Hage ${ }^{a,}$ \\ aDepartment of Chemistry, University of Nebraska, Lincoln, Nebraska, 68588-0304 (USA) \\ ${ }^{b}$ Department of Pharmaceutical Sciences, Texas Tech University Health Sciences Center, \\ Amarillo, Texas (USA)
}

\begin{abstract}
Carbamazepine and imipramine are drugs that have significant binding to human serum albumin (HSA), the most abundant serum protein in blood and a common transport protein for many drugs in the body. Information on the kinetics of these drug interactions with HSA would be valuable in understanding the pharmacokinetic behavior of these drugs and could provide data that might lead to the creation of improved assays for these analytes in biological samples. In this report, an approach based on peak profiling was used with high-performance affinity chromatography to measure the dissociation rate constants for carbamazepine and imipramine with HSA. This approach compared the elution profiles for each drug and a non-retained species on an HSA column and control column over a board range of flow rates. Various approaches for the corrections of non-specific binding between these drugs and the support were considered and compared in this process. Dissociation rate constants of $1.7( \pm 0.2) \mathrm{s}^{-1}$ and $0.67( \pm 0.04) \mathrm{s}^{-1}$ at pH 7.4 and $37^{\circ} \mathrm{C}$ were estimated by this approach for HSA in its interactions with carbamazepine and imipramine, respectively. These results gave good agreement with rate constants that have determined by other methods or for similar solute interactions with HSA. The approach described in this report for kinetic studies is not limited to these particular drugs or HSA but can also be extended to other drugs and proteins.
\end{abstract}

\section{Keywords}

Peak profiling; High-performance affinity chromatography; Carbamazepine; Imipramine; Human serum albumin; Drug-protein binding

(C) 2010 Elsevier B.V. All rights reserved.

*Author for correspondence. Phone: (402) 472-2744; FAX: (402) 472-9402 dhage@unlserve.unl.edu.

Publisher's Disclaimer: This is a PDF file of an unedited manuscript that has been accepted for publication. As a service to our customers we are providing this early version of the manuscript. The manuscript will undergo copyediting, typesetting, and review of the resulting proof before it is published in its final citable form. Please note that during the production process errors may be discovered which could affect the content, and all legal disclaimers that apply to the journal pertain. 


\section{INTRODUCTION}

Human serum albumin (HSA) is the most abundant protein in serum [1]. This protein has a molar mass of $66.5 \mathrm{kDa}$ and is known to have reversible binding to a large number of drugs, hormones and other small solutes in the circulation. This binding is important in determining the transport, excretion and metabolism of such substances in the body [1,2]. The kinetics of these interactions can also be important in determining the distribution and metabolic halflife of drugs [1].

Carbamazepine and imipramine (see Figure 1) are two drugs that are known to have significant binding to HSA. Carbamazepine is used to treat seizures and bipolar disorder and has an affinity for HSA in the range of $10^{-3}-10^{-4} \mathrm{M}^{-1}$ [3-5], with this binding occurring at a single site on HSA (i.e., Sudlow site II) with an association equilibrium constant of $5.3 \times$ $10^{3} \mathrm{M}^{-1}$ at $\mathrm{pH} 7.4$ and $37^{\circ} \mathrm{C}$ [5]. Imipramine is a tricyclic antidepressant [6] that also binds to Sudlow site II of HSA, but which has an association equilibrium constant at this site of $1.6 \times 10^{5} \mathrm{M}^{-1}$ [7]. Although the strength of these drug interactions with HSA has been considered in a number of previous reports [3-5,7], there is little information on the kinetics of these interactions. Obtaining such kinetic information could be useful in providing a better understanding of the behavior of these drugs in the body $[2,8]$.

There are several techniques that are used to examine the rates of solute-protein interactions, including surface plasmon resonance (SPR), stopped flow techniques, filtration assays, and various chromatographic methods [9-13]. SPR is best suited for use with systems that have moderate to strong affinities, stopped flow techniques require solutes or interactions that can be measured by methods such as fluorescence, and filtration assays have limited sampling rates [11-13]. Chromatographic techniques based on high-performance affinity chromatography (HPAC) and band-broadening measurements, peak decay analysis or the split peak method have also been reported for kinetic studies; however, these methods have limitations as well [10,14-20]. Band-broadening studies work well for systems that have fast association and dissociation kinetics but require the precise measurement of peak variances on multiple columns and at many flow rates [14-20]. Peak decay analysis is more suitable for systems with moderate rates of dissociation if mobile phase mass transfer is negligible, which generally requires work with small columns and high flow rates [10,20]. The split peak method makes use of peak area measurements of a non-retained analyte fraction to determine association rate constants; this approach works best for systems with strong binding and slow dissociation kinetics and again typically requires the use of small columns and high flow rates [17,21].

One variation on the band-broadening method in HPAC that has been of interest in recent studies of solute-protein binding is an approach known as peak profiling $[9,10,22]$. In this method, band-broadening measurements are made for both the solute of interest and a nonretained solute on an affinity column that contains a binding agent. This information is then used along with chromatographic theory to estimate the dissociation rate constant for the retained solute as it interacts with the binding agent. It has been shown in work with model systems that this approach can be used to examine the interactions of solutes with HSA [22], making this method attractive for measuring drug dissociation rates from this protein. This previous work included a validation versus reference techniques for an analyte (i.e., Ltryptophan) that is similar to carbamazepine in its affinity for HSA and that has the same binding site on this protein as both carbamazepine and imipramine [5,7,9,10,16,22]. In this current study, the peak profiling method will be used to examine the binding of carbamazepine and imipramine with HSA. It will be shown as part of this work how peak profiling can be used to correct for the non-specific binding of these and other drugs to a 
chromatographic support, as achieved by expanding the theory of this approach to include systems with multi-site interactions.

\section{THEORY}

Eqn. (1) shows the reversible reaction model that was used in this study to describe the binding of a drug or small solute (A) with an immobilized binding agent or protein (P) $[22,23]$. In this model, the association equilibrium constant $\left(\mathrm{K}_{\mathrm{a}}\right)$ is equal to ratio of the second-order association rate constant $\left(\mathrm{k}_{\mathrm{a}}\right)$ and the first-order dissociation rate constant $\left(\mathrm{k}_{\mathrm{d}}\right)$ for the binding of A with P.

$$
\mathrm{A}+\mathrm{P} \underset{\mathrm{k}_{\mathrm{d}}}{\stackrel{\mathrm{k}_{\mathrm{a}}}{\rightleftarrows}} \mathrm{AP} \quad \mathrm{K}_{\mathrm{a}}=\frac{\mathrm{k}_{\mathrm{a}}}{\mathrm{k}_{\mathrm{d}}}
$$

A similar reversible model was used to describe the binding of A with non-specific sites on a support.

In the peak profiling method, the first and second statistical moments for an injected analyte are used to determine the retention time and variance for this solute on a column containing $\mathrm{P}$. The variance is, in turn, related to the various band-broadening processes that occur during passage of A through the column, such as eddy diffusion, mobile phase mass transfer, stagnant mobile phase mass transfer, longitudinal diffusion, and stationary phase mass transfer [22,24].

Most previous work with the peak profiling method has been carried out by using measurements at a single flow rate under conditions in which stationary phase mass transfer is the dominant source of band-broadening. Under such conditions, the measured retention time and variance of the retained analyte, as well as the elution time and variance of a nonretained species, can be used with Eqn. (2) to estimate the value of the dissociation rate constant $\mathrm{k}_{\mathrm{d}}$ for the interaction of A with $\mathrm{P}[9,25]$.

$$
\mathrm{k}_{\mathrm{d}, \mathrm{s}}=\frac{2 \mathrm{t}_{\mathrm{M}}^{2}\left(\mathrm{t}_{\mathrm{R}}-\mathrm{t}_{\mathrm{M}}\right)}{\sigma_{\mathrm{R}}^{2} \mathrm{t}_{\mathrm{M}}^{2}-\sigma_{\mathrm{M}}^{2} \mathrm{t}_{\mathrm{R}}^{2}}
$$

The terms $t_{R}$ and $\sigma_{R}^{2}$ in this equation are the retention time and variance of the peak for the injected analyte, while $t_{M}$ and $\sigma_{R}{ }^{2}$ are the void time and variance of the peak for the nonretained species. This method not only requires that stationary phase mass transfer be the main source of band-broadening, but Eqn. (2) also assumes that all other sources of bandbroadening are negligible or the same for the retained and non-retained species $[9,10,22]$.

It has been shown recently that the peak profiling approach can be used over a broader range of flow rates by using the following form of Eqn. (2) $[9,10,22]$.

$$
\mathrm{H}_{\mathrm{R}}-\mathrm{H}_{\mathrm{M}}=\frac{2 \mathrm{u} \mathrm{k}}{\mathrm{k}_{\mathrm{d}}(1+\mathrm{k})^{2}}=\mathrm{H}_{\mathrm{k}}
$$

In this expression, $\mathrm{H}_{\mathrm{R}}$ is the total plate height measured for analyte $\mathrm{A}$ on a column containing binding agent $\mathrm{P}$, and $\mathrm{H}_{\mathrm{M}}$ is the total plate height measured on the same column for a non-retained solute. The term $\mathrm{k}$ is the retention factor for the analyte, $\mathrm{u}$ is the linear velocity of the mobile phase, and $\mathrm{H}_{\mathrm{k}}$ is the plate height contribution due to stationary phase 
mass transfer. According to Eqn. (3), a plot of $\left(\mathrm{H}_{\mathrm{R}}-\mathrm{H}_{\mathrm{M}}\right)$ versus $\mathrm{u} \mathrm{k} /(1+\mathrm{k})^{2}$ should result in a linear relationship, with a best-fit slope that will give the value of $\mathrm{k}_{\mathrm{d}}$ if all sources of bandbroadening other than $\mathrm{H}_{\mathrm{k}}$ are negligible or approximately the same for the analyte and nonretained solute.

Both Eqns. (2) and (3) are for a model in which there is only one type of binding site for the analyte in the column. However, it is possible to expand these relationships for use with a two-site model, as shown in Eqn. (4) (see derivation provided in the Supplemental Information) [26].

$$
\mathrm{H}_{\mathrm{R}}-\mathrm{H}_{\mathrm{M}}=\frac{\mathrm{uk}}{(1+\mathrm{k})^{2}} \cdot\left(\frac{2 \alpha_{\mathrm{HSA}}}{\mathrm{k}_{\mathrm{d}, \mathrm{HSA}}}+\frac{2 \alpha_{\mathrm{n}}}{\mathrm{k}_{\mathrm{d}, \mathrm{n}}}\right)=\frac{2 \mathrm{u} \mathrm{k}_{\mathrm{HSA}}}{\mathrm{k}_{\mathrm{d}, \mathrm{HSA}}(1+\mathrm{k})^{2}}+\frac{2 \mathrm{u} \mathrm{k}_{\mathrm{n}}}{\mathrm{k}_{\mathrm{d}, \mathrm{n}}(1+\mathrm{k})^{2}}
$$

In this particular set of equations, the two-site model is used to describe an analyte with specific binding to HSA (i.e., representing P in Eqn. (1)) as well as non-specific binding by the same analyte to the support. The term $\mathrm{k}_{\mathrm{d}, \mathrm{HSA}}$ in this case represents the dissociation rate constant for the analyte with HSA. The term $\mathrm{k}_{\mathrm{HSA}}$ is the retention factor for the analyte that is due to the interactions of A with HSA, and $\alpha_{\mathrm{HSA}}$ is the fraction of the total retention factor that is due to the binding of A with HSA. The term $\mathrm{k}_{\mathrm{d}, \mathrm{n}}$ represents the dissociation rate constant for A with its non-specific sites, $\mathrm{k}_{\mathrm{n}}$ is the retention factor for $\mathrm{A}$ that is due to this non-specific binding, and $\alpha_{\mathrm{n}}$ is the fraction of the total retention factor that is due to this non-specific binding. Eqn. (4) again predicts a linear relationship for a plot of $\left(\mathrm{H}_{\mathrm{R}}-\mathrm{H}_{\mathrm{M}}\right)$ versus $\mathrm{u} \mathrm{k} /(1+\mathrm{k})^{2}$ in a two-site system, but the slope of this plot will now be influenced by the dissociation rate constants for the analyte at its various binding sites as well as the degree of analyte retention that is created by each of these interactions.

If the second type of interaction in a two-site model is due to non-specific binding of the analyte to the support, as is illustrated in Eqn. (4), the dissociation rate constant and retention factor for this interaction can be obtained through independent peak profiling studies for the analyte on a control column. The retention data obtained on the control column can then also be used with the retention data from a column containing binding agent P (i.e., HSA in this study) to estimate the values of $\alpha_{H S A}$ and $\alpha_{n}$ in Eqn. (4) [24]. For example, the total retention factor $\mathrm{k}$ for an analyte on an HSA column can be described by Eqn. (5),

$$
\begin{aligned}
\mathrm{k} & =\mathrm{k}_{\mathrm{HSA}}+\mathrm{k}_{\mathrm{n}} \\
& =\mathrm{k}_{\mathrm{HSA}}+\left(1-\mathrm{f}_{\mathrm{HSA}}\right) \mathrm{k}_{\text {control }}
\end{aligned}
$$

in which $\mathrm{f}_{\mathrm{HSA}}$ is the fraction of the column surface area that occupied by the immobilized HSA. This latter value can be estimated by using the measured protein content of the support and the approximate dimensions of HSA (or P) [27]. The values of $\alpha_{n}$ and $\alpha_{\mathrm{HSA}}$ can then be found by using the following expressions.

$$
\alpha_{\mathrm{n}}=\left(1-\mathrm{f}_{\mathrm{HSA}}\right) \mathrm{k}_{\text {control }} / \mathrm{k}
$$

$$
\alpha_{\mathrm{HSA}}=1-\alpha_{\mathrm{n}}
$$

By using this set of equations, it is possible to use the peak profiling results obtained on both an HSA and a control column to correct for the effects of non-specific binding and to 
estimate the dissociation rate constant for the analyte with HSA, as will be illustrated in Section 4 using carbamazepine and imipramine as examples.

\section{EXPERIMENTAL}

\subsection{Reagents}

The HSA (Cohn fraction V, essentially fatty acid free, $\geq 96 \%$ pure), carbamazepine and imipramine were obtained from Sigma-Aldrich (St. Louis, MO). The Nucleosil Si-300 silica (7 $\mu \mathrm{m}$ particle diameter, Á pore size) was purchased from Macherey Nagel (Düren, Germany). Reagents for the bicinchoninic acid (BCA) protein assay were from Pierce (Rockford, IL). All other chemicals used were reagent-grade or better. All aqueous solutions were prepared with water obtained from a Nanopure water system (Barnstead, Dubuque, IA) and filtered by using Osmonics $0.22 \mu \mathrm{m}$ nylon filters from Fisher (Pittsburgh, PA).

\subsection{Apparatus}

The chromatographic system consisted of a LC-10AD pump, a SPD-10AV UV/Vis detector, and an SCL-10A system controller (Shimadzu, Columbia, MD). Samples were injected by using a SpectraSystem AS3000 autosampler (Thermo separations, Waltham, MA) equipped with a $5 \mu \mathrm{L}$ sample loop. All columns and mobile phases were maintained at a constant temperature of $37.0( \pm 0.1)^{\circ} \mathrm{C}$ by using a water jacket from Alltech (Deerfield, IL) and a 9100 circulating water bath from Fisher. The columns were downward slurry-packed by using an HPLC column slurry packer from Alltech. Chromatographic data were collected using programs written in LabView 5.0 or 8.0 (National Instruments, Austin, TX) and were analyzed using PeakFit 4.12 (Systat Software, San Jose, CA).

\subsection{Column Preparation}

The Nucleosil Si-300 was converted into diol-bonded silica, as described previously [28]. The diol coverage of the resulting support was $235( \pm 20) \mu \mathrm{mol}$ diol groups ( \pm 1 S.D.) per gram of silica, as determined by an iodometric capillary electrophoresis assay [29]. HSA was immobilized onto the diol-bonded silica by using the Schiff base method [30]. A control support was made from the same batch of diol-bonded silica by using the Schiff base method but with no HSA being added during the immobilization step. The final HSA supports used in this work contained $47( \pm 3)$ to $57( \pm 3) \mathrm{mg}$ HSA per gram of silica, as determined in triplicate by a BCA protein assay using HSA as the standard and the control support as the blank [31]. The HSA support and control support were downward slurrypacked at 24-28 MPa (3500-4000 psi) into separate $5 \mathrm{~cm} \times 4.6 \mathrm{~mm}$ i.d. stainless steel columns using $\mathrm{pH} 7.4,0.067 \mathrm{M}$ potassium phosphate buffer as the packing solution. These columns were stored at $4{ }^{\circ} \mathrm{C}$ in $\mathrm{pH} 7.4,0.067 \mathrm{M}$ potassium phosphate buffer when not in use.

\subsection{Chromatographic Experiments}

The mobile phase used in this study was $\mathrm{pH} 7.4,0.067 \mathrm{M}$ potassium phosphate buffer. The samples each drug or sodium nitrate (i.e., which was used as a non-retained solute in this study) were prepared in this mobile phase. All chromatographic studies were carried out in triplicate. The elution of carbamazepine, imipramine, and sodium nitrate was monitored at $285 \mathrm{~nm}, 205 \mathrm{~nm}$, or $205 \mathrm{~nm}$, respectively. All experiments were performed within one year of column preparation and each column was used for less than 220 injections. Previous studies have shown that similar HSA columns are stable and show no significant signs of degradation under these conditions [16].

The final peak profiling experiments were performed by injecting $30 \mu \mathrm{M}$ carbamazepine, 25-30 $\mu \mathrm{M}$ sodium nitrate, or $100 \mu \mathrm{M}$ imipramine on the HSA column, control column, and a 
zero volume spacer/union at flow rates ranging from 1.0 to $4.0 \mathrm{ml} / \mathrm{min}$. These sample concentrations were selected through studies such as those described in Section 4.1 and were based on conditions and guidelines that have been identified previously as being suitable for use in peak profiling [22]. The retention time (i.e., first statistical moment) and variance (second statistical moment) of each chromatographic peak were obtained by using Peakfit 4.12 with an exponentially-modified Gaussian (EMG) fit and the linear progressive baseline plus residual options of this program.

\section{RESULTS AND DISCUSSION}

\subsection{Selection of Conditions for Peak Profiling}

Several factors were considered in selecting the conditions for the peak profiling measurements that were used in this report. For instance, in order to mimic physiological conditions, all peak profiling experiments were performed at $37^{\circ} \mathrm{C}$ and at $\mathrm{pH}$ 7.4. The concentrations of the injected solutes were also considered. It is known from previous work that the concentration of an injected solute can affect the apparent dissociation rate constant that is obtained by the peak profiling method $[9,10,22]$. Ideally, this sample concentration should represent linear elution conditions but should still provide a sufficient signal for the reliable measurement of an injected solute's retention time and peak variance $[9,10]$.

The effects of varying the sample concentration of carbamazepine on the measured retention time and variance for this solute on an HSA column are shown in Figure 2. These results were obtained on a $5 \mathrm{~cm} \times 4.6 \mathrm{~mm}$ i.d. HSA column at a flow rate of $0.5 \mathrm{ml} / \mathrm{min}$, but similar trends would be expected at other flow rates $[9,10,22]$. As the sample concentration of carbamazepine was increased, and in particular above $25-30 \mu \mathrm{M}$, a decrease in the apparent retention time and an increase in the peak variance were seen. These changes were expected as non-linear elution conditions began to be present at the higher sample concentrations (see Ref. [22] for a further discussion of these effects and guidelines to avoid them in peak profiling studies). Similar experiments with sodium nitrate showed no significant change in the measured elution time or variance for this non-retained solute (data not shown). There was a corresponding increase in the uncertainty of the measured elution times and variances for both carbamazepine and sodium nitrate as the sample concentration was decreased, as illustrated by the error bars in Figure 2. Thus, as a compromise between precision and accuracy, $25-30 \mu \mathrm{M}$ was selected as the sample concentrations that were used in all later work for carbamazepine and sodium nitrate.

The next stage of this study explored the use of the single flow rate method of peak profiling method at higher flow rates and linear velocities to estimate the dissociation rate constant $\mathrm{k}_{\mathrm{d}}$. This was necessary because Eqn. (2) requires the use of a flow rate that is sufficiently high to make stationary phase mass transfer the dominant process in band-broadening $[9,10,22]$. However, it was found in preliminary studies that a sufficiently high flow rate could not be reached with the given columns to obtain a steady value for $\mathrm{k}_{\mathrm{d}}$ by the single flow rate method (data not shown). Instead, only an upper estimate for $\mathrm{k}_{\mathrm{d}}$ could be made by this approach, giving a maximum value of $5.6( \pm 0.3) \mathrm{s}^{-1}$ for carbamazepine on the HSA column. In all further work described in this report, a method based on Eqn. (3), or related expressions, and measurements made at multiple flow rates was instead used to overcome the need to work at a single high flow rate when determining $\mathrm{k}_{\mathrm{d}}$ for the interaction of carbamazepine, and imipramine, with HSA [9,10,22].

\subsection{Peak Profiling on the Control Column}

It was noted early in this study that carbamazepine had measurable non-specific binding to the support used in the columns, even when no HSA was present. This type of non-specific binding has been seen in previous work with carbamazepine on similar materials and 
columns [5,32]. Figure 3 shows some typical chromatograms that were obtained for carbamazepine and sodium nitrate on the control column used in this study. The retention factor for carbamazepine on this column was determined to be $\mathrm{k}_{\text {control }}=2.45( \pm 0.01)$, which was found later to represent approximately $36 \%$ of the total retention measured for carbamazepine on the HSA column after a correction had been made for the surface coverage of the immobilized protein.

The rate of dissociation for carbamazepine from these non-specific interaction sites was determined by carrying out peak profiling studies for this drug on the control column. This was done by injecting both carbamazepine and sodium nitrate on the control column at flow rates ranging from 1 to $4 \mathrm{ml} / \mathrm{min}$, as shown in Figure 4. A plot of $\left(\mathrm{H}_{\mathrm{R}}-\mathrm{H}_{\mathrm{M}}\right)$ versus u k/ $(1+\mathrm{k})^{2}$ for this data gave a good fit to a linear response, with a correlation coefficient of $0.9768(n=7)$ being obtained. When the slope of this plot was examined according to Eqn. (3) and a single-site binding model, the dissociation rate constant for carbamazepine with the support control was estimated to be $\mathrm{k}_{\mathrm{d}, \mathrm{n}}=4.6( \pm 0.4)$. This value was then used along with the measured retention factor of carbamazepine on the same support to later correct for the effects of these non-specific interactions when using peak profiling to examine the dissociation of carbamazepine from the HSA column (see next section).

\subsection{Peak Profiling on the HSA Column}

After the dissociation of carbamazepine from the control support had been examined, peak profiling studies were next carried out for this drug on the HSA column. Typical chromatograms that were obtained in these studies are shown in Figure 5, in which carbamazepine eluted at about $4.5 \mathrm{~min}$ at $1 \mathrm{ml} / \mathrm{min}$ and in less than $1.5 \mathrm{~min}$ at $4 \mathrm{ml} / \mathrm{min}$. The overall retention factor measured for carbamazepine on the HSA column was $5.12( \pm 0.01)$. However, it was also known from work in the previous section that part of this total retention was due to non-specific interactions of carbamazepine with the support.

Figure 6 shows the results when the data for carbamazepine on the HSA column were analyzed by using a plot of $\left(\mathrm{H}_{\mathrm{R}}-\mathrm{H}_{\mathrm{M}}\right)$ versus $\mathrm{u} /(1+\mathrm{k})^{2}$. A linear fit was obtained with a correlation coefficient of $0.9954(n=6)$. It was not possible from this fit alone to distinguish between single-site or multi-site interactions because either model would predict a linear relationship for this type of plot, as indicated by Eqns. (3) and (4). If it was assumed that only single-site binding was present and Eqn. (3) was used to examine these results, an apparent dissociation rate constant of $2.6( \pm 0.3) \mathrm{s}^{-1}$ would be obtained from this plot. However, it was known from the prior experiments with the control column that some nonspecific interactions were present, which would lead to an error in an estimate of $k_{d}$ that was based on only a single-site model for the HSA column. The next phase of this work, as described in Section 4.4, sought to combine the results for the control column and HSA column to make a correction for the contribution of these non-specific interactions in the peak profiling measurements.

\subsection{Corrections for Multi-site Interactions}

One approach that was to correct for the contribution of the non-specific interactions was to assume that the contribution of these sites to the overall retention of carbamazepine was the same on the control column and HSA column. This assumption neglected the fact that the immobilization of HSA will block some of these non-specific sites. Such an assumption was made by setting $\mathrm{f}_{\mathrm{HSA}}$ approximately equal to zero in Eqns. (5) and (6). This approach was useful in obtaining an initial lower estimate of $\mathrm{k}_{\mathrm{d}}$ for the interaction of carbamazepine with HSA. In this case, the value of $\alpha_{n}$ in Eqn. (6) was found by simply using the ratio of the measured retention factors for carbamazepine on the control column and the HSA column. This method gave an estimate for $\alpha_{n}$ of $0.46( \pm 0.02)$ and a corresponding value for $\alpha_{H S A}$ of 
0.54 ( \pm 0.02$)$ based on Eqn (7). These fractions were then used in Eqn. (4) along with data from Figure 5, the measured retention factors for carbamazepine on the HSA and control columns, and the dissociation rate constant estimated in Section 4.2 for carbamazepine on the control support. The result was an estimated dissociation rate constant for carbamazepine with HSA of $1.4( \pm 0.1) \mathrm{s}^{-1}$, a value which now contained a correction for non-specific binding but not for the surface coverage of HSA on the support.

A second, more detailed correction was next made that did consider the fact that some of the non-specific interactions were blocked in the presence of immobilized HSA. This correction was made by utilizing the measured protein content of the HSA support and a cross sectional area for a single HSA molecule of $5600 \AA^{2}[1,27]$. This information gave a value for $\alpha_{\mathrm{HSA}}$ of $0.63( \pm 0.02)$ and a revised estimate for $\alpha_{n}$ of $0.37( \pm 0.02)$. When these numbers were used along with the data from Figure 5, the measured retention factors for carbamazepine on the HSA and control columns, and the estimated dissociation rate constant for carbamazepine on the column support, the corrected $k_{d}$ value for carbamazepine with HSA was $1.7( \pm 0.2) \mathrm{s}^{-1}$. This value was slightly higher (i.e., $\left.18 \%\right)$ than the value obtained when no correction for the coverage of HSA was made and represented the best estimate of the dissociation rate constant for carbamazepine with HSA. Based on this value of $\mathrm{k}_{\mathrm{d}}$ and a previously-measured association equilibrium constant of $5.3( \pm 0.8) \times 10^{3} \mathrm{M}^{-1}$ that has been reported under similar experimental conditions for carbamazepine at Sudlow site II (i.e., the single major binding site for carbamazepine on HSA) [5], the corresponding association rate constant for carbamazepine at the same site on HSA was determined to be $9.0( \pm 1.7) \times 10^{3}$ $\mathrm{M}^{-1} \mathrm{~s}^{-1}$.

Although there are no known previous studies that have examined the dissociation rate of carbamazepine from HSA and there are no standard methods that could be used to easily examine the kinetics of this interaction, the results obtained in this report do agree with rate constants that have been measured for other solutes with HSA. For example, L-tryptophan is a solute that also binds to Sudlow site II of HSA and that has an association equilibrium constant only slightly higher than the value for carbamazepine at this site (i.e., $1.1 \times 10^{4} \mathrm{M}^{-1}$ versus $\left.5.3 \times 10^{3} \mathrm{M}^{-1}\right)[5,23]$. In the case of L-tryptophan, dissociation rate constants in the range of 3 to $6 \mathrm{~s}^{-1}$ have been reported with HSA when using methods such as stopped flow fluorescence analysis, band-broadening studies and peak profiling $[9,16,22]$. These results are similar to the final value of $1.7 \mathrm{~s}^{-1}$ that was estimated in this report for the dissociation of carbamazepine from HSA.

\subsection{Peak Profiling Studies with Imipramine}

The general approach used in this study to examine carbamazepine-HSA dissociation was also explored for use with imipramine. Like carbamazepine, imipramine was found to have appreciable levels of non-specific binding to the support used in these studies. The retention factor on the control column was $14.5( \pm 0.3)$ for imipramine and made up roughly $32 \%$ of the total retention seen for this drug on the HSA columns.

The dissociation rate of these non-specific interactions was studied by first carrying out peak profiling experiments for imipramine on a control column and analyzing these data according to Eqn. (3). In this case it was found that imipramine gave a best-fit line with a slope that was statistically equal to zero (i.e., a slope that agreed with a reference value of zero when compared at the $95 \%$ confidence level). This result indicated that the dissociation rate constant for the non-specific interactions of this particular drug with the support was larger than could be determined directly when using peak profiling. It was possible, however, to obtain a lower limit for this dissociation rate constant by using either the slope of a plot that was prepared according to Eqn. (3) or by using both this slope and its 
associated precision. These approaches gave an estimated value for $\mathrm{k}_{\mathrm{d}, \mathrm{n}}$ of at least $130 \mathrm{~s}^{-1}$, which represented fast dissociation of imipramine from non-specific sites on the support.

The next set of experiments used peak profiling to determine the dissociation rate constant for imipramine on an HSA column. The plot of $\left(\mathrm{H}_{\mathrm{R}}-\mathrm{H}_{\mathrm{M}}\right)$ vs. $\mathrm{u} k /(1+k)^{2}$ that was obtained for this drug is provided in Figure 7. This plot was found to give good linear behavior, with a correlation coefficient of $0.972(n=7)$ and only a random distribution of the residuals about the best-fit line. If it was assumed that only single-site binding was present and Eqn. (3) was used to examine these results, the apparent dissociation rate constant that was obtained from the slope of the plot for imipramine on the HSA column was $1.28( \pm 0.01) \mathrm{s}^{-1}$ (see Table 1). However, it was also known that these interactions included both non-specific binding by the drug to the support and binding by this drug with HSA. Thus, corrections for these non-specific interactions were next made by using the same techniques as described in Section 4.4 for carbamazepine.

It was first assumed when correcting for the non-specific interactions that the contribution of non-specific interactions to the overall retention of imipramine was the same on the control column and HSA column, or that $\mathrm{f}_{\mathrm{HSA}}$ was approximately equal to zero in Eqns. (5) and (6). This method gave values of $\alpha_{n}=0.68( \pm 0.02)$ and $\alpha_{\mathrm{HSA}}=0.32( \pm 0.02)$ for imipramine. The resulting dissociation rate constant that was then estimated for imipramine with HSA by this approach was $0.41( \pm 0.04) \mathrm{s}^{-1}$. The second approach used to correct for the non-specific interactions made an adjustment for the fact that some of the non-specific interactions were blocked in the presence of immobilized HSA, as described in the previous section. The value of $\alpha_{\mathrm{HSA}}$ that was estimated by this approach was $0.52( \pm 0.03)$ for imipramine. The dissociation rate constant calculated by this method was $0.67( \pm 0.04) \mathrm{s}^{-1}$ for imipramine and represented the best-estimate that was made for this parameter in this study.

The dissociation rate constant determined in this report for imipramine with HSA was close to a value of $0.29( \pm 0.11) \mathrm{s}^{-1}$ that has been recently estimated by using a peak decay method with a similar HSA support [33]. This dissociation rate constant also agrees with estimated $\mathrm{k}_{\mathrm{d}}$ values of $0.35 \mathrm{~s}^{-1}$ to $0.66 \mathrm{~s}^{-1}$ that have been reported for warfarin with HSA [15,20,33], a system with a similar affinity to that present in the interaction of imipramine with HSA [7]. Based on a dissociation rate constant of $0.67( \pm 0.04) \mathrm{s}^{-1}$ and an association equilibrium constant of $1.6( \pm 1.0) \times 10^{5} \mathrm{M}^{-1}$ for imipramine at its high affinity site on HSA [7], the corresponding association rate constant for imipramine with HSA was calculated to be 1.1 $( \pm 0.7) \times 10^{5} \mathrm{M}^{-1} \mathrm{~s}^{-1}$.

\section{CONCLUSION}

The peak profiling method was used in this study to determine the dissociation rate constants for the drugs carbamazepine and imipramine with both immobilized HSA and a control support. This work was carried out with a method that used retention times and peak variances that were acquired over a range of flow rates. It was shown how this method could be used in a system with multi-site interactions and to correct for the effects of non-specific binding in drug-protein binding studies (see summary of results in Table 1). The final estimates obtained for the dissociation rate constant of carbamazepine and imipramine with HSA showed good agreement with values reported for HSA with other solutes (i.e., Ltryptophan or warfarin) or that had been obtained for the same interactions by other methods $[9,15,16,20,22,33]$. This information should lead to a better understanding of how carbamazepine and imipramine are transported in the circulation.

The peak profiling method that was described in this work is not limited to carbamazepine and imipramine or HSA but should be suitable for use as a relatively fast and accurate 
method for studying the kinetics of other drug-protein interactions [9,10,22]. For instance, the technique for dealing with multi-site systems that was developed in this report could be utilized in situations other than those that involve specific binding to a protein and nonspecific binding to a support. The same approach could be used to examine the dissociation rates for a solute from both a specific, saturable binding site and non-specific, high capacity or non-saturable regions on a protein. This latter type of study could be carried out by conducting peak profiling experiments for the solute in the presence and absence of a mobile phase that contains a sufficient concentration of a site-specific probe that can be used to saturate and block the specific sites during part of the study. A similar strategy using siteselective probes could be used to examine the dissociation of a solute from a protein with multiple binding sites, as might be needed to examine a drug that binds to both Sudlow sites I and II of HSA. The applications tested in this study and these other possible uses of this approach indicate that peak profiling should be a valuable tool in the future study of multisite interactions in pharmaceutical and biochemical research.

\section{Supplementary Material}

Refer to Web version on PubMed Central for supplementary material.

\section{Acknowledgments}

This work was supported by the National Institutes of Health under grants R01 GM044931 and R01 NS052484. These studies were conducted in facilities that were renovated under NIH grant RR015468.

\section{REFERENCES}

1. Peters, TJ, Jr.. All About Albumin: Biochemistry, Genetics and Medical Applications. Academic Press; San Diego, CA: 1995.

2. Herve F, Urien S, Albengres E, Duche JC, Tillement JP. Clin. Pharmacokin. 1994; 26:44.

3. MacKichan JJ, Zola EM. Br. J. Clin. Pharmacol. 1984; 18:487. [PubMed: 6487490]

4. Lai CM, Moore P, Quon CY. Res. Comm. Mol. Pathol. Pharmacol. 1995; 88:51.

5. Kim HS, Hage DS. J. Chromatogr. B. 2005; 816:57.

6. Preskorn SH, Dorey RC, Jerkovich GS. Clin. Chem. 1988; 34:822. [PubMed: 3131042]

7. Yoo MJ, Hage DS. J. Chromatogr. B. 2009; 877:1149.

8. Ascoli GA, Domenici E, Bertucci C. Chirality. 2006; 18:667. [PubMed: 16823814]

9. Talbert AM, Tranter GE, Holmes E, Francis PL. Anal. Chem. 2002; 74:446. [PubMed: 11811421]

10. Schiel JE, Hage DS. J. Sep. Sci. 2009; 32:1507. [PubMed: 19391173]

11. Rich RL, Day YSN, Morton TA, Myszka DG. Anal. Biochem. 2001; 296:197. [PubMed: 11554715]

12. Fitos I, Visy J, Kardos J. Chirality. 2002; 14:442. [PubMed: 11984760]

13. Rietbrock N, Lassmann A. Naunyn-Schmiedeberg's Arch. Pharmacol. 1980; 313:269. [PubMed: 7432558]

14. Chaiken IM. Anal. Biochem. 1979; 97:1. [PubMed: 484830]

15. Loun B, Hage DS. Anal. Chem. 1996; 68:1218. [PubMed: 8651495]

16. Yang J, Hage DS. J. Chromatogr. A. 1997; 766:15. [PubMed: 9134727]

17. Hage DS, Walters RR, Hethcote HW. Anal. Chem. 1986; 58:274. [PubMed: 3963388]

18. Anderson DJ, Walters RR. J. Chromatogr. 1986; 376:69.

19. Muller AJ, Carr PW. J. Chromatogr. 1984; 284:33.

20. Chen J, Schiel JE, Hage DS. J. Sep. Sci. 2009; 32:1632. [PubMed: 19472288]

21. Renard J, Vidal-Madjar C. J. Chromatogr. A. 1994; 661:35. [PubMed: 8136911]

22. Schiel JE, Ohnmacht CM, Hage DS. Anal. Chem. 2009; 81:4320. [PubMed: 19422253]

23. Hage DS. J. Chromatogr. B. 2002; 768:3.

J Chromatogr A. Author manuscript; available in PMC 2012 April 15. 
24. Walters, RR. Analytical Affinity Chromatography. Chaiken, IM., editor. CRC Press; Boca Raton, FL: 1987. p. 117-156.

25. Denizot FC, Delaage MA. Proc. Natl. Acad. Sci. U.S.A. 1975; 72:4840. [PubMed: 1061072]

26. Schiel, JE. Ph.D. Dissertation. University of Nebraska; Lincoln: 2009.

27. Chen J, Ohnmacht C, Hage DS. J. Chromatogr. B. 2004; 809:137.

28. Larsson PO. Methods Enzymol. 1984; 104:212. [PubMed: 6371445]

29. Chattopadhyay A, Hage DS. J. Chromatogr. A. 1997; 758:255. [PubMed: 9042737]

30. Loun B, Hage DS. Anal. Chem. 1994; 66:3814. [PubMed: 7802261]

31. Smith PK, Krohn RI, Hermanson GT, Mallia AK, Gartner FH, Provenzano MD, Fujimoto EK, Goeke NM, Olson BJ, Klenk DC. Anal. Biochem. 1985; 150:76. [PubMed: 3843705]

32. Kim HS, Mallik R, Hage DS. J. Chromatogr. B. 2006; 837:138.

33. Yoo MJ, Hage DS. J. Chromatogr. A. in press. 


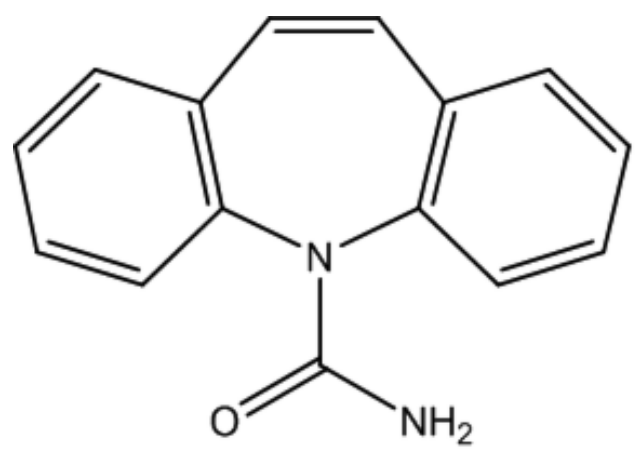

\section{Carbamazepine}

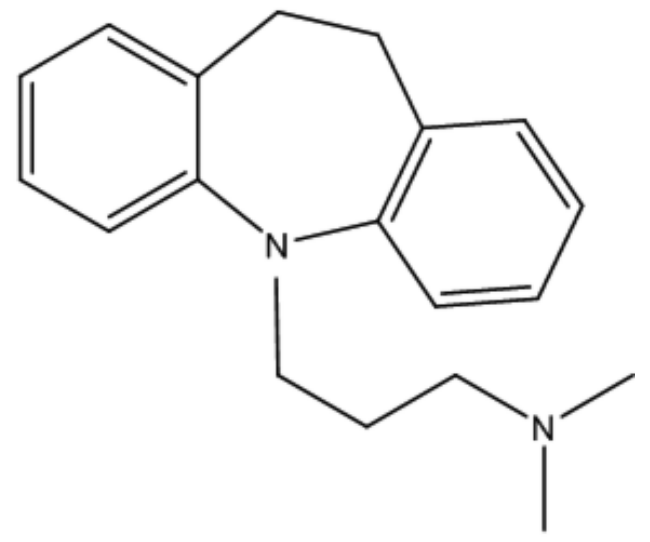

Imipramine

Figure 1.

Structures of carbamazepine and imipramine. 

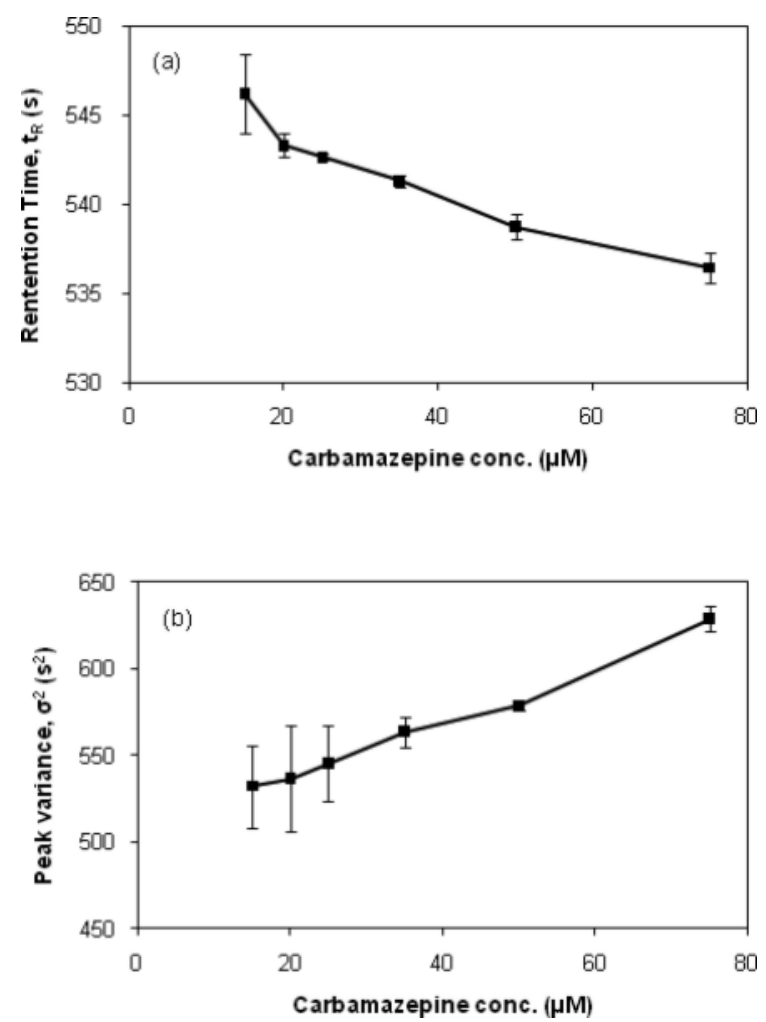

Figure 2.

Effects of sample concentration on (a) the measured retention times and (b) measured peak variances for carbamazepine on an HSA column at $0.5 \mathrm{ml} / \mathrm{min}$. The error bars in these plots represent a range of \pm 1 S.D. for triplicate injections. 

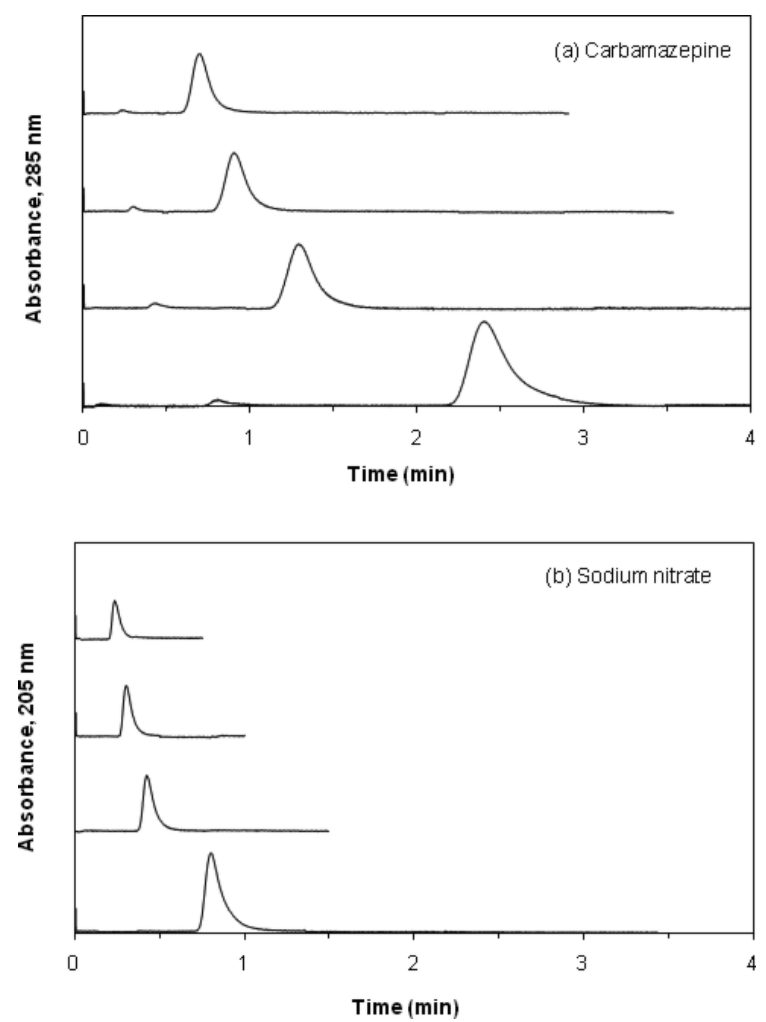

Figure 3.

Typical chromatograms for (a) carbamazepine and (b) sodium nitrate on a control column at flow rates (bottom-to-top) of 1, 2, 3, and $4 \mathrm{ml} / \mathrm{min}$. 


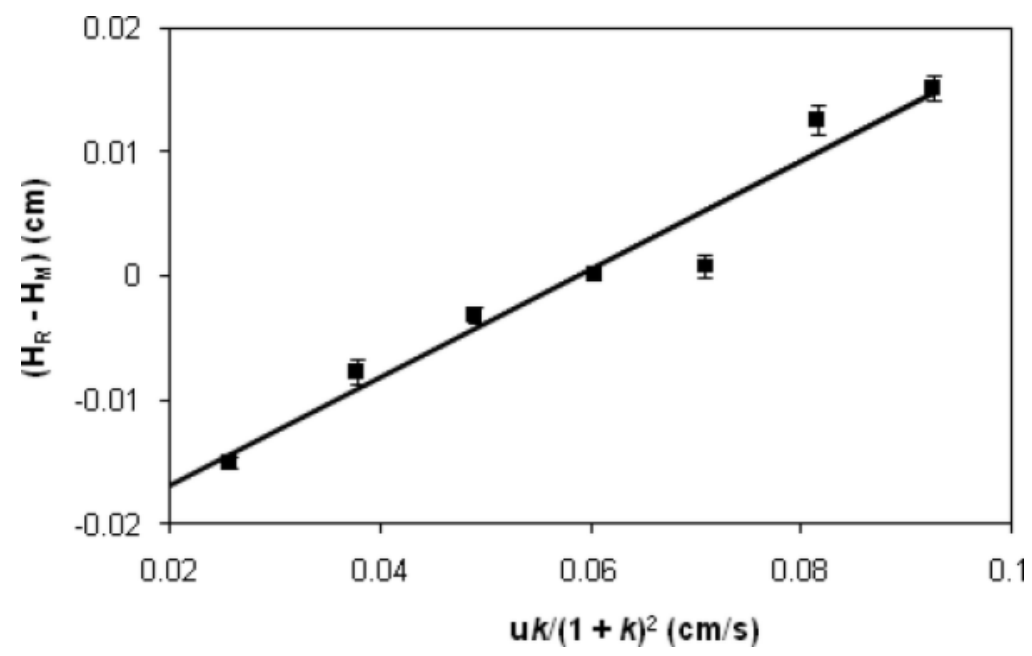

Figure 4.

Plot prepared according to Eqn. (3) for injections of carbamazepine and sodium nitrate on the control column. The equation for the best-fit line is $y=(0.435 \pm 0.043) x-(0.0255 \pm$ $0.0027)$, with a correlation coefficient of $0.9768(n=7)$. The error bars represent a range of \pm 1 S.D. for triplicate injections. 

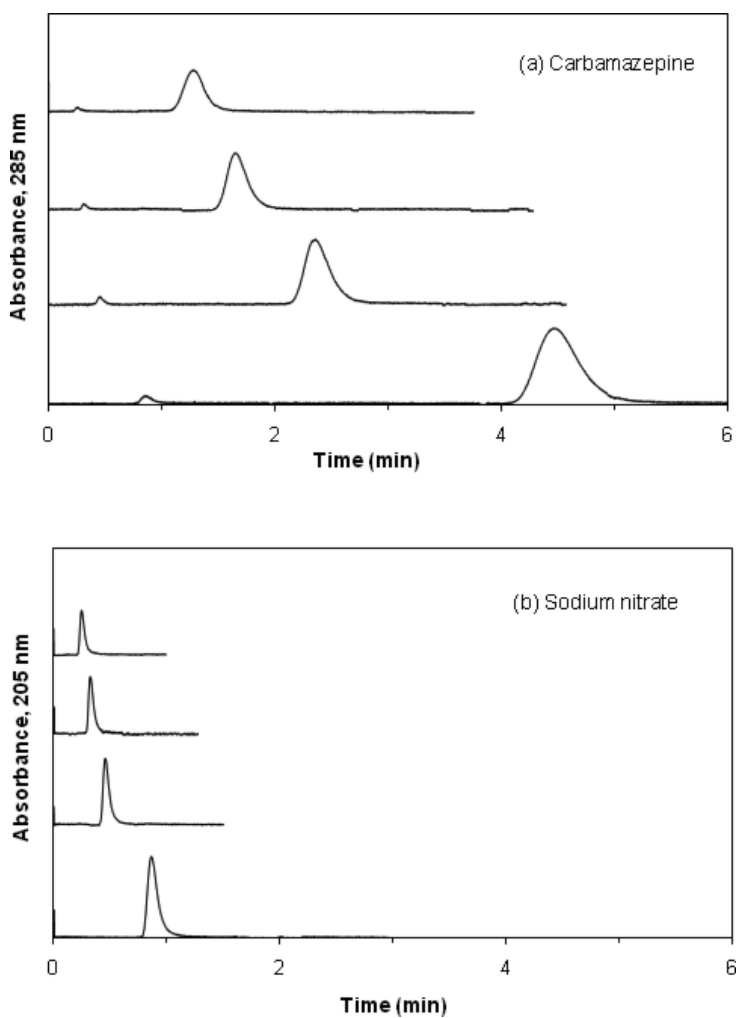

Figure 5.

Typical chromatograms for (a) carbamazepine and (b) sodium nitrate on the HSA column at flow rates (bottom-to-top) of 1, 2, 3, and $4 \mathrm{ml} / \mathrm{min}$. 


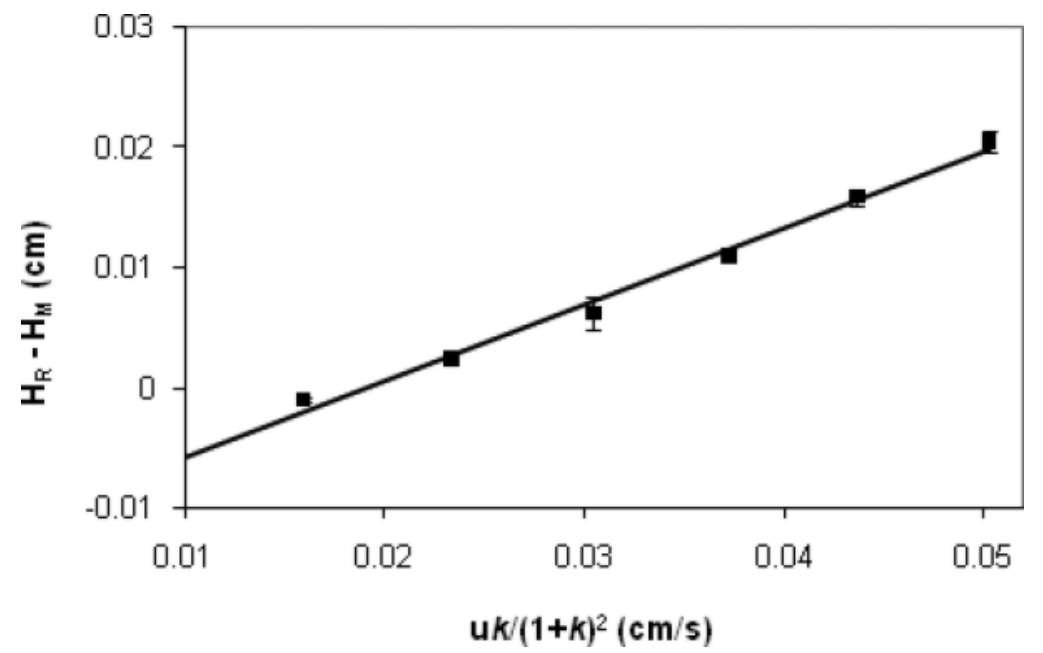

Figure 6.

Plot prepared according to either Eqn. (3) or Eqn. (4) for injections of carbamazepine and sodium nitrate on the HSA column. The equation for the best-fit line is $y=(0.6351 \pm$ $0.0307) x-(0.0121 \pm 0.0011)$, with a correlation coefficient of $0.9954(n=6)$. The error bars represent a range of \pm 1 S.D. for triplicate injections. 


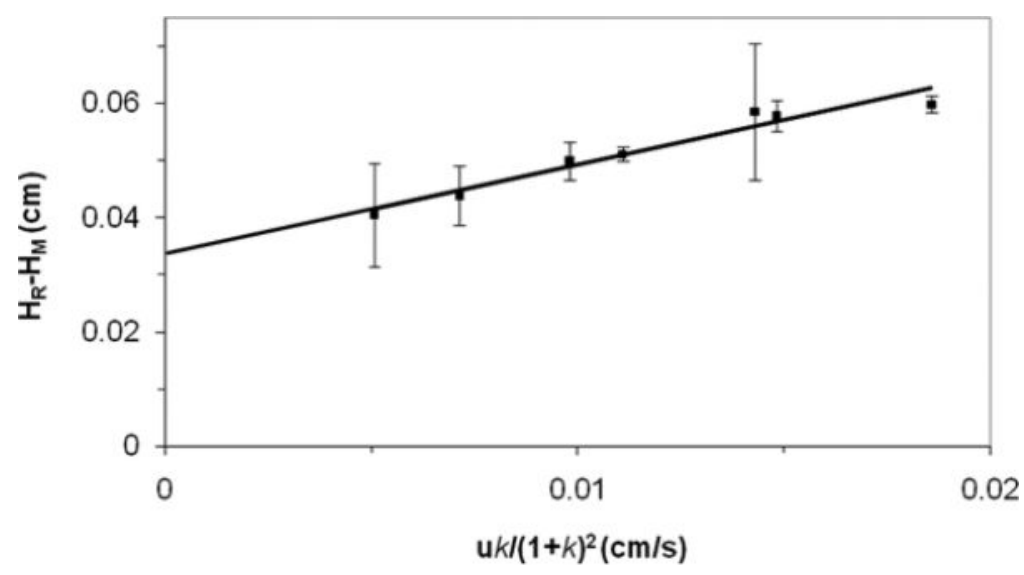

Figure 7.

Plot prepared according to Eqns. (3) or (4) for injections of imipramine and sodium nitrate on the HSA column. The equation for the best-fit line was $y=1.56( \pm 0.017) x+0.034( \pm$ $0.002)$, with a correlation coefficient of $0.972(n=7)$. The error bars represent a range of \pm 1 S.D. for triplicate injections. 


\section{Table 1}

Estimated dissociation rate constants for carbamazepine and imipramine with HSA at $37{ }^{\circ} \mathrm{C}$ and $\mathrm{pH} 7.4$

\begin{tabular}{lcc}
\hline Data analysis method & \multicolumn{2}{c}{ Dissociation rate constant, $\mathbf{k}_{\mathbf{d}}\left(\mathbf{s}^{-\mathbf{1}}\right)^{\boldsymbol{a}}$} \\
Single-site model & Carbamazepine & Imipramine \\
Two-site model (no correction for surface coverage of HSA) & $1.4( \pm 0.1)$ & $1.28( \pm 0.01)$ \\
Two-site model (with correction for surface coverage of HSA) & $1.7( \pm 0.2)$ & $0.41( \pm 0.04)$ \\
\hline
\end{tabular}

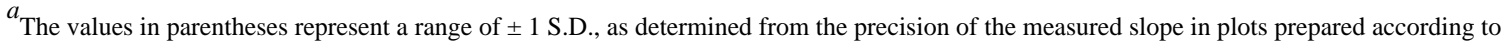
Eqns. (3)-(4) and by using error propagation. 


\section{SUPPORTING INFORMATION}

Derivation of Eqn. (4). It is possible by using mass balance to estimate the individual contributions to the plate height due to stationary phase mass transfer $\left(\mathrm{H}_{\mathrm{k}}\right)$ for a system with multi-site interactions, as originally proposed by Giddings [1]. This can be accomplished by describing the binding regions in a column as a set of distinct interaction sites, each of which has its own association rate constant $\left(\mathrm{k}_{\mathrm{a}}\right)$ and dissociation rate constant $\left(\mathrm{k}_{\mathrm{d}}\right)$ for an analyte $\mathrm{A}$, as shown below.

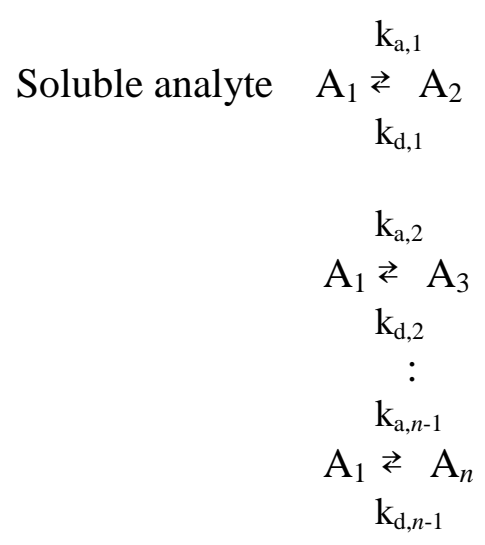

In this model there are $n$ possible states for the analyte. State $\mathrm{A}_{1}$ represents the soluble analyte in the mobile phase, while states $A_{2}$ through $A_{n}$ represent the analyte that is bound to a series of unique sites (i.e., 1 to $n-1$ types of sites). To simplify this model, it is assumed that once the analyte has been bound by one of these sites, it cannot bind to a different site at the same time. The only way A can go from one type of bound state to another is by first being released from the first site, entering the soluble state $A_{1}$ in the mobile phase, and then interacting with another site to form a new bound state.

The relative mole fraction of the analyte in each state can be represented by the terms $X_{1}$ through $X_{n}$, where the summation of all $X$ values must be equal to one. These fractions can also be related to the overall observed retention factor for the analyte $(k)$ by using mass balance, where the term $k_{i}$ represents the contribution to the overall retention factor due to the interaction 
of $\mathrm{A}$ at a particular type of site $\mathrm{I}$, where $k_{\mathrm{i}}=\left(\mathrm{mol} \mathrm{A}\right.$ in state $\mathrm{A}_{\mathrm{i}}$ bound at site $\left.\mathrm{i}\right) /(\mathrm{mol} \mathrm{A}$ present as state $A_{1}$ in mobile phase).

$$
1=X_{1}+X_{2}+X_{\mathrm{n}}=\frac{1}{(1+k)}+\sum_{i=2}^{n} \frac{k_{\mathrm{i}}}{(1+k)}
$$

The following plate height equation for stationary phase mass transfer has been previously derived to describe a system with multi-site binding, as given in Eqns. (A1)-(A3) [1].

$$
\mathrm{H}_{\mathrm{k}}=2 \cdot \mathrm{u} \cdot X_{1} \sum_{i=2}^{n} \frac{X_{\mathrm{i}}}{\mathrm{k}_{\mathrm{d}, \mathrm{i}}}
$$

Substitution of Eqn. (A4) into Eqn. (A5) yields the expression shown in Eqn. (A6).

$$
\mathrm{H}_{\mathrm{k}}=2 \cdot \mathrm{u} \frac{1}{(1+k)^{2}} \sum_{i=2}^{n} \frac{k_{\mathrm{i}}}{\mathrm{k}_{\mathrm{d}, \mathrm{i}}}
$$

Eqn. (A6) can then be rewritten in the form given in Eqn. (A7) by defining $\alpha_{i}$ as the fraction of the total retention factor that is due to the interaction of $\mathrm{A}$ at site $\mathrm{i}$, where $\alpha_{\mathrm{i}}=k_{\mathrm{i}} / k$.

$$
\mathrm{H}_{\mathrm{k}}=2 \cdot \mathrm{u} \frac{k}{(1+k)^{2}} \sum_{i=2}^{n} \frac{\alpha_{\mathrm{i}}}{\mathrm{k}_{\mathrm{d}, \mathrm{i}}}
$$

One useful feature of Eqn. (A7) is it can be expanded to include a system with any number of unique binding sites (e.g., $\mathrm{i}=2$ through $n$, or a total of $n-1$ separate binding regions for a system with $n$ possible states for A).

It has been shown previously that the relationship $\left(\mathrm{H}_{\mathrm{R}}-\mathrm{H}_{\mathrm{M}}\right)=\mathrm{H}_{\mathrm{k}}$ is valid if all plate height contributions except $\mathrm{H}_{\mathrm{k}}$ are the same or negligible when comparing the band-broadening for retained and non-retained solutes [2]. In this situation, Eqn. (A7) predicts that a plot of $\left(\mathrm{H}_{\mathrm{R}}\right.$ $\left.\mathrm{H}_{\mathrm{M}}\right)$ versus $\frac{\mathrm{u} \cdot k}{(1+k)^{2}}$ will give a slope of $\Sigma \frac{2 \cdot \alpha_{\mathrm{i}}}{\mathrm{k}_{\mathrm{d}, \mathrm{i}}}=\frac{2}{\mathrm{k}_{\mathrm{d}, \mathrm{app}}}$ where $\mathrm{k}_{\mathrm{d}, \text { app }}$ is the apparent dissociation rate constant predicted for a system with only a single type of binding site for the 
analyte. From this slope, the value of $\mathrm{k}_{\mathrm{d}, \mathrm{i}}$ for the site of interest can be obtained by using the definition of $\alpha_{\mathrm{i}}$, as given earlier, and the fact that $1=\Sigma \alpha_{\mathrm{i}}$ if $k, k_{\mathrm{i}}$ and $\mathrm{k}_{\mathrm{d}, \mathrm{i}}$ for all other binding sites in the system are known or can be independently measured.

\section{References}

[1] J.C. Giddings, Dynamics of Chromatography, Marcel Dekker: New York, 1965.

[2] J.E. Schiel, C.M. Ohnmacht, D. S. Hage, Anal. Chem. 81 (2009) 4320. 